\title{
“El dictador ideal”. El SEMANario OMEga: \\ UN PERIÓDICO DE LA DERECHA RADICAL MEXICANA (1939-1942)*
}

Rubén García Vega**

\section{Resumen}

Acercamiento al discurso de una derecha radical mexicana en los años 1939-1942, a partir de la categoría: el "dictador ideal", construida por el autor de este artículo con base en el análisis del gobernante deseable, expuesto por uno de los portavoces de la derecha radical: el trisemanario Omega. De ese modo, en el texto se propone una tipología para identificar el modelo de mandatario que los redactores del periódico querían para México. Por ejemplo, algunas de las características principales que Omega reconocía en los dictadores de aquel momento eran: fe religiosa, profesión castrense, nacionalismo y carácter antidemocrático.

Palabras clave: derecha radical, prensa anticardenista, prensa política, fascismo

\section{Abstract}

An approach to the discourse of a mexican extreme right during the years 1939-1942, as of the category: the "ideal dictator", built by the autor of this paper based on the analysis of the desirable ruler, exposed by one of the spokespersons of the extreme right: the three times a week journal Omega. Thus, the text exhibits a typology for identifying the model of ruler that the editors of the journal wanted for Mexico. For example, some of the main characteristics that Omega recognized in dictators of that moment were: religious faith, military profession, nationalism and anti-democratic character.

Keywords: radical right, anti-cardenista press, political press, fascismo.

\footnotetext{
* Este artículo retoma los resultados de mi tesis de licenciatura en Historia, presentada en el Instituto Mora en abril de 2013.

** Licenciado en historia por el Instituto Mora; rgarciav89@gmail.com
} 
El siglo xx estuvo caracterizado por grandes $\mathrm{y}$ acelerados cambios en todo el mundo. Fue el siglo que vio caer los poderosos imperios de ultramar como el inglés, el francés y el alemán; un siglo que fue testigo de dos masivas y destructivas guerras mundiales que en su momento, redefinieron la estructura social, política, económica y cultural de la época. Fue un siglo de ideologías radicales y de grandes movimientos de masas que demandaban cambios sociales y políticos en las estructuras de poder en casi todo el mundo. La sociedad también se transformó con la llegada de la radio, la aviación, la televisión, las computadoras y otros grandes avances de la ciencia que hoy dominan nuestra vida cotidiana.

La primera mitad del siglo xx fue un periodo tan convulso que representó un momento particularmente propicio para la manifestación de "individuos excepcionales", de personajes cuya voluntad se impuso ante "circunstancias excepcionales". ${ }^{1}$ En efecto, en este periodo aparecieron en la escena política internacional hombres como Benito Mussolini, Adolf Hitler, Vladimir Ilich Uliánov (Lenin) y Josef Stalin; así como también Francisco Franco, Winston Churchill, Franklin D. Roosevelt y Charles De Gaulle. Porque un “estado de excepción” —una guerra, una crisis o una revolución, tiempos en que los sistemas políticos, jurídicos y sociales dejan de funcionar - saca a la luz a ciertos individuos que destacan, que manifiestan habilidades especiales para hacer frente a las circunstancias y que tienen la capacidad de imponer su voluntad a un conjunto social. De acuerdo con el historiador francés Patrice Gueniffey, la aparición de hombres excepcionales en determinados momentos tiene una explicación. ${ }^{2}$

1 Gueniffey, "La voluntad en la historia", p. 7.

2 Historiador contemporáneo, estudioso de la Revolución francesa. Investigador del Centro de Estudios Sociológicos y Políticos Raymond Aron. Escuela de Altos Estudios en Ciencias Sociales de París. 
En su artículo "La voluntad de la historia" afirma:

El surgimiento de "hombres excepcionales" se encuentra ligado al estado de excepción, en el sentido amplio del término, y la figura del "hombre excepcional" se confunde casi con la del dictador; es decir, un individuo al cual las circunstancias excepcionales otorgan poderes extraordinarios, lo que lleva a subordinar el derecho a la voluntad. En el reino del derecho no hay hombres excepcionales; éstos intervienen cuando el derecho desaparece, ya sea porque no responde a las exigencias de la situación (guerra) o porque ha sido destruido (revolución). El estado de excepción realiza lo que no se presenta nunca en tiempo normal, el poder puro y la dominación pura; el arquetipo de poder, es decir el reino absoluto de su voluntad que tiene los medios de romper cualquier resistencia; el arquetipo de la dominación, es decir que quien da una orden "encuentra una obediencia pronta, automática, estereotipada". Claro, tal situación favorece el desarrollo de las cualidades individuales, buenas o malas. ${ }^{3}$

Según Gueniffey, las circunstancias excepcionales tienen el poder de revelar diversas cualidades del hombre, incluidas las monstruosas. El autor habla de "una poderosa voluntad hasta entonces escondida o embrionaria en circunstancias normales", ${ }^{4}$ en la que también influye la existencia de un estado de excepción. Pero guía u opresor, un hombre excepcional es "un individuo al cual las circunstancias excepcionales otorgan poderes extraordinarios, lo que lleva a subordinar el derecho a la voluntad". ${ }^{5}$

¿Cómo han sido vistos estos "hombres excepcionales" en su momento?, ¿cómo fueron vistos, por ejemplo, desde México? Y de manera más específica, ¿cómo fueron vistos los "dictadores" de la primera mitad del siglo xx por la derecha radical mexicana? Porque a principios del siglo, México también había pasado por una profunda crisis y había vivido diez años de guerra civil; porque para la década de 1940, que es la que aquí tocamos, había sectores sociales en México muy descontentos con los gobiernos posrevolucionarios. Estos descontentos miraban cómo en

3 Ibid., pp. 7-8.

4 Gueniffey, "La voluntad en la historia tad", p. 7.

5 Ibid., pp. 7-8. 
Europa destacaban hombres "de orden" a los que podían considerar dignos de imitación.

Para hacernos una idea de lo que pensaban y querían estos descontentos, nos propusimos revisar el discurso del periódico Omega, inscrito en un significativo movimiento de la derecha mexicana de esos años: la derecha radical secular mexicana. ${ }^{6}$ Para acercarnos a este discurso creamos una categoría de análisis: el "dictador ideal". A partir de esta categoría hemos analizado cuáles eran las características de ese "dictador ideal", es decir, del gobernante deseable para uno de los portavoces de esa derecha radical: el trisemanario Omega. Desde luego que éste nunca habló de un "dictador ideal", nosotros hemos elaborado esta expresión como un medio para analizar su discurso. A partir de aquello que Omega señalaba como positivo o negativo de diferentes dictadores, propusimos una tipología que nos ha facilitado entender cuál era el modelo de gobernante que se quería para México. Armamos nuestra tipología a partir de algunas de las principales características que Omega reconocía en diferentes líderes y gobernantes, de manera muy especial, en los dictadores del momento: su fe religiosa, su profesión castrense, su nacionalismo y xenofobia, su carácter antidemocrático y su compromiso con una economía planeada.

De esta manera, a partir de Omega y de su "dictador ideal" este artículo busca acercarse al proyecto que un sector de la derecha radical mexicana tenía para México. El trisemanario dio un lugar especial a esos personajes que encabezaron cambios políticos, económicos y geográficos importantes en el mundo occidental, en esas tormentosas circunstancias de la primera mitad del siglo $\mathrm{xx}$, se hizo una valoración particular de cada uno de ellos, que es lo que analizaremos. Entender cómo Omega calificaba a los dictadores cuyas acciones desembocaron en la segunda guerra mundial nos permitirá entender algo del pensamiento del sector de la derecha mexicana representado por este periódico, de su resistencia a las políticas de los gobiernos posrevolucionarios en México e incluso, de su proyecto de nación.

6 La derecha radical secular era el conjunto de movimientos nacionalistas populares, de corte autoritario, separados de la corriente derechista que pertenecía a la Iglesia y que surgió como una reacción en contra de la Revolución mexicana y de los cambios sociales que prometía. Campbell, La derecha radical, p. 7. 
Entre los individuos "excepcionales" que interesaban a Omega, y a partir de los cuales construimos a su "dictador ideal”, están Adolf Hitler y Benito Mussolini. Ambos personajes aprovecharon la situación de crisis por la que atravesaban los grandes imperios europeos para "brillar"; mostraron su "talento" y capacidades políticas frente a pueblos que se encontraban desesperados y quebrados por la que hasta entonces había sido la guerra más mortífera que se había vivido y que había sumido al mundo en un caos político, económico y social. Otro de estos personajes admirados por Omega era Francisco Franco, quien en los años previos a la segunda guerra mundial y frente a una situación política de cambios e inestabilidad en España, con los republicanos en el gobierno, tomó el poder por la vía militar. Franco se hizo de un nombre, terminó con el régimen republicano y gobernó España de una manera autoritaria durante poco más de tres décadas.

De igual manera, Omega reconocía como especial al Mariscal Philippe Pétain, el héroe francés de la batalla de Verdún quien años más tarde, se alió con la Alemania nazi y permitió la instauración de un gobierno títere en mayo de 1940. También daba un lugar, si bien secundario, a Fulgencio Batista, para el caso latinoamericano. Con una valoración negativa, figuraba igualmente en las páginas de Omega otro gran líder-dictador de la época: Josef Stalin, quien había sabido aprovechar la invasión de Alemania a la Unión Soviética, en junio de 1941, para consolidar su liderazgo y guiar a la URSS en la "Gran Guerra Patriótica" contra Hitler.

El presente artículo se centra en el análisis de la forma en que Omega veía y valorizaba a estos líderes que gobernaron de manera autoritaria e incluso, totalitaria. ${ }^{7}$ En su momento, las acciones de estos líderes fueron vistas como infames y atroces por unos ojos, pero por otros fueron admiradas y elogiadas. Este último fue el caso de Omega, el trisemanario conservador, en la década de 1940.

7 Algunos de ellos representaron regímenes fascistas, si bien, como Franco Savarino explica, no todo totalitarismo es fascista. El fascismo, de acuerdo con este autor, fue una respuesta político-cultural novedosa a los múltiples cambios y desafíos que ocurrieron entre $1900 \mathrm{y}$ 1930. Más concretamente fue una respuesta categórica a la crisis de la civilización occidental, al avance de las ciencias antropológicas y sociológicas, a los problemas de individualismo y atomismo social, a la lucha de clases, a la pérdida de influencia y centralidad de Europa, a la rebelión generacional, al avance de la guerra mundial, una respuesta crítica al bolchevismo ruso y la búsqueda de una "tercera vía". Savarino, "Fascismo en América Latina", p. 46. 


\section{México en los veinte y los treinta}

En la década de los veinte, México iniciaba una etapa de recuperación económica tras una dura guerra civil. Durante la primera mitad del siglo xx el país fue testigo del último gran conflicto armado entre la Iglesia y el Estado, un acontecimiento que definiría la postura de las diversas facciones políticas en la década de los treinta y cuarenta. El conservadurismo y el ferviente clericalismo en México inspiraron a grupos que manifestaron su admiración por los emergentes sistemas totalitarios en Europa como el fascismo italiano, el nacionalsocialismo alemán y el falangismo español, así como por sus carismáticos líderes. Estos grupos también exteriorizaron su rechazo al gobierno del general Lázaro Cárdenas, quien de 1934 a 1940, encabezó una administración de izquierda, promotora del reparto agrario, de las reivindicaciones obreras, de la expropiación petrolera y de una educación "socialista".

El México posrevolucionario, en particular el de finales de los veinte y de la década de 1930, representó un periodo de construcción y consolidación de instituciones. Algunos de los años más difíciles por el enfrentamiento entre los gobiernos posrevolucionarios y grupos conservadores fueron los de la rebelión cristera, en los que las fuerzas federales se enfrentaron a insurrectos y clérigos que rechazaban los intentos del nuevo Estado y de las políticas de Calles, que buscaban controlar la vida religiosa de los mexicanos y quitarle poder a la Iglesia. También fueron difíciles los años que siguieron a la expropiación petrolera, por el rechazo que esta medida provocó a nivel internacional y por la manera en que esa actitud golpeaba a la economía interna, situación agravada por coincidir con una crisis en el precio internacional de la plata, que era una de las principales producciones mexicanas.

Con Lázaro Cárdenas al frente del gobierno, de 1934 a 1940, Omega alcanzó un protagonismo muy especial por su pronunciada oposición a las políticas cardenistas. El periódico se lanzó con fuerza en contra de la política progresista y de compromiso social del nuevo presidente, que tocaron intereses importantes y movilizaron a élites e incluso, a clases medias en su contra. Por eso alcanzó un protagonismo especial. Una de las banderas de Omega fue su rechazo a la reforma educativa: protestaba por la modificación 
al artículo 3 constitucional que introducía la educación "socialista". Las reacciones en contra de esta reforma tuvieron lugar en todo el país. Omega combatió la iniciativa presidencial desde sus páginas publicadas en la capital. ${ }^{8}$ Las ideas socialistas, en general, fueron rechazadas por Omega, que las consideraban como ajenas a la cultura nacional, y culpaba de su arribo a México al propio general Cárdenas. La expropiación petrolera de 1938 también lo enfrentó con el régimen cardenista.

Omega fue un trisemanario de contenido abiertamente político. Contaba con unos cuantos artículos informativos, pero estaba compuesto, más bien, por un conjunto de editoriales, artículos de crítica y propaganda política. La divisa de este periódico era "Nada que no sea justo. Ni nada que no sea cierto". Con este lema los editores del periódico se presentaban a su público como fieles a un punto de vista objetivo, pero también como sostén de ideas "justas", es decir, que además de informar, se manifestaban comprometidos políticamente: emitirían juicios. En realidad, se trataba de un periódico de combate, más que de análisis político. Utilizaba un lenguaje provocador; apelaba más a la emotividad que a la racionalidad; carecía de un discurso sistemático; respondía a las coyunturas y sus afirmaciones no eran siempre coherentes. Su compromiso era, con una propuesta muy conservadora, que ellos creían apropiada para el país. En sus páginas se enfatizaba que: Omega "es un genuino órgano de la opinión pública. Sus artículos reflejan el sentimiento de quienes anhelan una patria mejor gobernada por hombres mejores". ${ }^{9}$ Este pequeño periódico político circuló en la ciudad de México entre los años 1918 y 1948.

Omega alcanzó su mayor presencia en la segunda mitad de los treinta y en los primeros años de la década de los cuarenta, cuando el gobierno de Cárdenas impulsó el reparto agrario, apoyó demandas obreras, expropió las compañías petroleras e impulsó una educación que llamó "socialista". Omega perdió postura cuando México se alineó en el bando aliado que luchaba en contra del fascismo. El periodo histórico abordado por este artículo va de 1939, año de inicio de la segunda guerra mundial, hasta 1942, cuando México declaró la guerra a los países del "Eje”. Y se limita a dilucidar la

8 Pérez Rosales, "Notas sobre anticardenismo", 1994, p. 188. Véase, por ejemplo: Omega, 13 de marzo y 10 de abril de 1937.

9 Santos del Valle, "Lombardo Toledano es judío", Omega, 28 de enero de 1939. 
idea que tenían los redactores de Omega acerca de cómo debía ser un buen gobernante. En el marco temporal definido, identificamos aquí algunas de las principales características de lo que podría ser el "dictador ideal" para Omega, basándonos en las opiniones, cualidades, atributos y defectos que el trisemanario encontraba en cinco grandes dictadores europeos de la época: Adolf Hitler, Benito Mussolini, Josef Stalin, Philippe Pétain y Francisco Franco, y en un latinoamericano: Fulgencio Batista.

\section{El dictador militar}

La capacidad militar era una característica fundamental del gobernante ideal de la derecha radical secular. Omega tendía a reconocer y a aplaudir la educación castrense y la destreza en acciones de armas de algunos líderes o jefes de Estado. Consideraba que un militar poseía la disciplina y la experiencia para ganar batallas, pero también para el ejercicio del poder. De esta manera elogiaba a los dirigentes de mano dura, militares de carrera y que eran, o que podrían llegar a serlo pronto, cabezas de gobiernos fuertes como los que sus redactores admiraban.

Un primer ejemplo de cómo, para este periódico, el carácter de militar podía aportar mucho al buen gobernante es el caso del general Fulgencio Batista. Su alianza con los estudiantes en 1933, pudo hacer pensar que su gobierno sería abierto y revolucionario, pero un anónimo columnista de Omega atribuía una tendencia conservadora a la profesión militar y, por tanto, también a Batista.

Para Omega, el general cubano era una promesa para la política de su país: "un hombre de carácter, que dentro de su medio, ha sabido y podido elevarse al importante papel que desempeña". Y si bien aceptaba que era un "radical", sostenía que lo era "pero de las derechas; como soldado que es. No es, no puede ser izquierdista. A ello se opone su propia profesión”. ${ }^{10}$ En opinión del columnista, la disciplina que imponía la carrera militar estaba indisociablemente ligada a una manera de entender la política: conservadora, autoritaria. De acuerdo con Omega, la posibilidad de que un militar de carrera fuera demócrata y revolucionario no existía. Por eso, en

10 Idem. 
principio, este periódico aplaudía y apoyaba a un militar profesional para gobernar Cuba.

Pero un mejor ejemplo de las cualidades militares era, según Omega, el del general Francisco Franco, líder del movimiento nacionalista español y opositor al gobierno de la república. En 1939, la guerra civil española estaba concluyendo y el triunfo del general sublevado parecía inminente. Omega conocía los antecedentes militares de Francisco Franco. Sus redactores sabían que había destacado como militar en las campañas del norte de África y pensaban que era un buen líder en la lucha contra lo que consideraban la anarquía de los republicanos. El "Generalísimo" Francisco Franco sería un buen gobernante para su país, sostenía Omega, y en sus columnas era exaltado como un verdadero "salvador" de España.

El "señor general Don Francisco Franco" era en toda la extensión y significado de la palabra, un verdadero genio militar para los columnistas de Omega. Más aún, su liderazgo era "salvador" para España y para muchos más: Franco era presentado en otra nota de Omega de ese mismo mes como $V$ aledor de todo el mundo bispano. ${ }^{11}$ Así, el militar salvador de España lo era de "nuestra España Grande", es decir, de México y de toda América Latina. ${ }^{12}$ Para Omega, el mérito del general era mayúsculo y por eso el Franco militar tenía un lugar muy especial como gran dictador.

Este hispanismo aplaudido por Omega y, en su opinión, representado por Franco, fue una doctrina político cultural que planteaba la existencia de una "gran familia", "comunidad" o "raza" trasatlántica que distinguía a todos los pueblos que, en un momento de su historia, habían pertenecido a la corona española. ${ }^{13}$ Esta doctrina no buscaba justificar acciones por parte de España para recuperar sus antiguas posesiones, pero sí aspiraba al ejercicio de algo cercano a una tutela espiritual por parte de la península sobre la América hispánica. ${ }^{14}$

Un tercer ejemplo de militar y jefe de Estado admirable para Omega era el mariscal Philippe Pétain. Este era el octogenario presidente de Francia,

11 Santos del Valle, "Reconocimiento inmediato del gobierno español o ruptura de relaciones con Albión y Francia", Omega, 23 de febrero de 1939.

12 Idem.

13 Pérez Montfort, Hispanismo y Falange, p. 15.

14 Idem. 
a quien Omega reconocía como a un gran patriota: primero, como el hábil militar que había ganado batallas decisivas para el triunfo de los aliados durante la primera guerra mundial, y luego, tras la invasión de Francia por la Alemania nazi, en junio de 1940, como la cabeza del régimen colaboracionista de Vichy. Sobre este personaje, Omega afirmaba que: "Cuando Pétain venció en Verdún, fue un gran patriota; y ahora, en 1940, a los ochenta y cuatro años de su edad, al convertirse en un gran dictador, TAMBIÉN ES UN GRAN PATRIOTA". ${ }^{15}$

Omega le atribuía un gran patriotismo al anciano mariscal, ya que el régimen de Vichy sostenía ideas reformistas nacionalistas con las que Omega se identificaba. Se reconocía también en su ideal de la familia, a la que veía como base de la sociedad, así como en su propuesta de sustitución de los viejos valores republicanos, a los que numerosos sectores de la élite política francesa parecían oponerse en el momento, en favor de un nuevo régimen autoritario, jerárquico y racialmente homogéneo.

Pétain, el héroe de Francia durante la primera guerra, representó durante la segunda el ideal de los sectores más conservadores de la derecha francesa, alguien para liderar un nuevo régimen el cual debía surgir de las cenizas de la derrota de mayo de 1940. El gobierno encabezado por Pétain impuso en Francia fuertes medidas de control económico y social -entre estas últimas, creó corporaciones sindicales y de juventudes francesas-, suprimió libertades y persiguió a los judíos. Buscaba mantener un "orden" en medio de la guerra, por eso Omega hablaba de él como "gran dictador".

Para ilustrar la importancia que tenían las cualidades militares del dictador para Omega es posible presentar todavía un cuarto ejemplo: Adolf Hitler. Aunque este no era soldado de carrera, estratega militar, ni nada relacionado con el ejercicio castrense, era un gran admirador del ejército. Omega sostenía que su liderazgo e ideología le habían permitido crear un fuerte y motivado ejército alemán:

El Führer había preparado y entrenado a la juventud alemana, desde hacía veinte años, para lograr un ejército netamente alemán, que lo llevara, no sólo a

15 Luis Orozco, "Los defensores de la democracia”, Omega, 27 de julio de 1940. 
hacer la guerra a todas partes, sino al triunfo definitivo, aplastante. El culto de este ejército es la patria, su objetivo y divisa, la represalia victoria. ${ }^{16}$

Así, para los columnistas de Omega, el verdadero aporte de Hitler al ejército había sido el haberlo dotado de una doctrina nacionalista capaz de impulsar al soldado alemán a combatir fanáticamente por la patria germana. ${ }^{17}$ Por otro lado, continuaban los redactores del periódico, Hitler conocía los acontecimientos históricos que habían llevado a la derrota de Napoleón por los rusos en 1812, conocía las estrategias y los errores de Napoleón y asumía que no cometería los mismos errores que el emperador francés. ${ }^{18}$ Esta afirmación de Omega tenía lugar en momentos en que las fuerzas armadas alemanas avanzaban implacables sobre el territorio ruso. Los partidarios de Alemania estaban confiados en un triunfo que un mes después, en las afueras de Moscú, se vendría abajo.

Cuatros ejemplos de dictadores con cualidades militares permiten mostrar la importancia que tenía para Omega la fuerza militar, la disciplina, el heroísmo en batalla. El dictador militar digno de toda la admiración de sus redactores, se encontraba personificado por el general Fulgencio Batista y por el mariscal Philippe Pétain, aunque su mejor exponente era el general Francisco Franco, en él confluían algunas otras de las "virtudes" de dictador, entre ellas la de abanderar un hispanismo en América. En Hitler, a pesar de no ser un militar, Omega reconocía a un inspirador de los ejércitos alemanes y a un estratega hecho en los libros y en el estudio de las campañas de los grandes generales.

16 Tomás Espinoza Corro, "La suicida indecisión de los ingleses. Opinión de un aliadófilo", Omega, 6 de noviembre de 1941.

17 De acuerdo con Canetti, el ejército es un elemento identitario fundamental del pueblo alemán. De alguna manera, el propio Hitler, sin ser militar, parece haber compartido o alimentado esa idea. Canetti dice que el "símbolo de masa" de los alemanes era el ejército. Canetti, Masa y poder, p. 169.

18 A pesar de que Hitler no fue militar de carrera, su vida estuvo muy influida por tratados militares de la guerra franco-prusiana de 1870, tal y como él afirma en Mi lucha: "Desde entonces me entusiasmó cada vez más todo aquello que tenía alguna relación con la guerra o con la vida militar". Hitler, Mi lucha, p. 5. 


\section{El dictador xenófobo y racista}

Otro rasgo característico de las ideas expresadas por Omega era su rechazo al extranjero, es decir su xenofobia además de su racismo. Omega admiraba al dictador racista y criticaba la presencia de extranjeros radicados en México, de españoles republicanos por ejemplo, pero muy especialmente la de los judíos. A estos últimos los acusaba de usurpar la nación y de despojarla de sus bienes, así como de animar un complot judeo-comunista que planeaba la destrucción de las instituciones y la vida "civilizada" del Estado mexicano.

Omega creía, al igual que lo creía Hitler, ${ }^{19}$ que la primera guerra mundial había sido un complot judío para desestabilizar al mundo occidental y privarlo de los valiosos cristianos en los que le daban fundamento: "La guerra universal de 1914-18, digan lo que quieran los que tratan de justificar la intromisión americana, fue la cristalización primera de múltiples esfuerzos judíos, para hundir al mundo de occidente, para desbaratar las cristiandades". ${ }^{20}$

Atrás de esta postura xenófoba de Omega estaba también la admiración que sentía por los dictadores europeos antisemitas. Por Hitler y Mussolini seguramente, pero también por el líder del régimen de Vichy, el viejo mariscal Pétain, quien había suprimido los derechos ciudadanos a los judíos franceses. En efecto, Pétain y sus ministros habían aprovechado la coyuntura excepcional de la derrota para llevar a cabo un ambicioso programa de "renovación" interna que incluía un nuevo orden políticamente autoritario, socialmente jerárquico y étnicamente homogéneo: ese proyecto fue la Revolución nacional. ${ }^{21}$ En particular por esta idea de sociedad étnicamente homogénea y limpia de elementos judíos, Omega le atribuía a Pétain el estatus de héroe nacional y le parecía reconocer en el fascismo francés, "la forma actual de organización política occidental". ${ }^{22}$

La postura de Omega frente al judaísmo en México, en particular, se puede apreciar claramente en un artículo de febrero de 1939, tras dar la

19 Hitler, Mi lucha, p. 62.

20 Santos del Valle, "Lombardo Toledano es judío", Omega, 28 de enero de 1939.

21 Reggiani, Los años sombríos. Francia en la era del fascismo (1934-1944), p. 48.

22 Vinicio R. de la Vega, "El fascismo en Francia”, Omega, 20 de julio de 1940. 
noticia de una serie de ataques realizados por algunos judíos a ciudadanos mexicanos:

De los dos hechos que aludimos, el primero, el verdaderamente escandaloso, se debió a que uno de tantos judíos que se han introducido al país, huyendo de la odiosidad que merecidamente les profesan los pueblos más consientes cultos, se permitió en la vía pública golpear a un mexicano que fue también ofendido con palabras denigrantes para nuestra nacionalidad, como lo dijeron los diarios. ${ }^{23}$

En el párrafo citado, Omega se refería al pueblo alemán principalmente, aunque en general a todos los antisemitas europeos que odiaban "merecidamente" a los judíos, como "pueblos más conscientes y cultos". De alguna manera, sugería el periódico, los mexicanos deberían seguir el ejemplo de estos pueblos "cultos" y no dejarse ofender por los judíos que usurpaban la patria. El texto de Omega continuaba de la siguiente manera:

La agresividad del judío que debe ser expulsado del país; sus frases denigrantes para nosotros los mexicanos, provocaron la justa indignación de los transeúntes que propalaron lo que acababan de ver y de escuchar, y en un momento, como era natural que sucediera se aglomeró la gente, vapulearon al judío que huyó internándose en un establecimiento mercantil de su propiedad. ${ }^{24}$

Para Omega, el judío era agresivo y el mexicano hacía bien en defenderse. Se justificaban de esta manera las acciones xenófobas de los mexicanos "ofendidos" y de los testigos que "vapulearon" al judío.

El redactor anónimo de esta columna concluía de la siguiente manera, con lo que dejaba ver otro motivo de prejuicio en contra de los judíos:

Otro episodio semejante se registró en el mercado de San Juan, desgraciada, fatalmente, hay que temer que en una mayor escala, estos casos se repitan como

23 "La libertad del pensamiento y del sufragio recibe el primer zarpazo de la imposición", Omega, 4 de febrero de 1939.

24 Idem. 
deplorables consecuencias, como pasa periódicamente en Rumania, Polonia y otros países de Europa, donde los judíos, como aquí y en todas partes, son un elemento de competencia desleal y de intensas perturbaciones. ${ }^{25}$

En estas líneas Omega atacaba a los judíos por la forma de hacer negocios: afirmaba que si prosperaban a donde quiera que fueran, era por su práctica sucia y desleal ante a los comercios nacionales. Se les atacaba por conspiradores, por promover el comunismo, por agresivos y por negociantes abusivos. Las acusaciones eran múltiples, incluso se les atacaba porque "son la raza más tradicionalista del universo y llamándose también progresistas, son el arquetipo de fanatismo elevado a la enésima potencia". ${ }^{26}$

Los columnistas de Omega reprobaban la entrada de los judíos al país desde los años veinte cuando el presidente Calles les había abierto las puertas, todavía perseguidos en Europa debido a la Revolución rusa y sin posibilidades de migrar a Estados Unidos por la fuerte crisis que se vivía en esos años. La manera que juzgaban estos hechos es digna de observarse en este párrafo:

Cuando empezaron a meterse los judíos, debido a que Calles inconscientemente o criminalmente les abrió las puertas, dijimos, desde hace más de diez años, o quince, que no tardaríamos en ver en México las escenas que provocaron en otros países los judíos, no toman las providencias precautorias que la experiencia indica. $^{27}$

El columnista anónimo que escribió esto consideraba la posibilidad de que la decisión del gobierno de Calles y las leyes migratorias expedidas por él, más que un error, hubieran sido auténticas acciones "criminales", es decir malintencionadas, que atentaban contra los derechos de los mexicanos. No explicaba el artículo cuáles derechos, pero Calles había sido identificado por los grupos conservadores entre 1920 y 1922 como "rojo", por el apoyo que brindaba a los obreros al agruparlos en la CROM, por lo que tras esta

25 Idem.

26 Santos del Valle, "Lombardo Toledano es judío", Omega, 28 de enero de 1939.

27 Idem. 
acusación podría haber la idea de que Calles abría las puertas no solo a los judíos, sino también a su comunismo "desestabilizador".

Pero la xenofobia de Omega no se limitó a su rechazo a los judíos, también puso de manifiesto su repudio a la llegada de refugiados españoles que huían, precisamente de la represión de los franquistas. Omega atacó al gobierno de Lázaro Cárdenas por muchas razones -por su programa de educación laica y por su compromiso con el reparto agrario, por ejemplo-, pero una más de ellas fue su apoyo al gobierno de la república española. El asilo a exiliados republicanos ofrecido por Cárdenas fue una acción que la derecha mexicana criticó fuertemente. Omega, como otros sectores de derecha -xenofóbos y nacionalistas exaltados- repudiaban el recibimiento de españoles republicanos.

El rechazo de Omega contra los refugiados españoles no era, ciertamente, contra todo español. Era un rechazo contra los "rojos", los respaldados por los "bolcheviques" de Stalin, quien según el periódico, querían hacer llegar sus doctrinas a México:

Es evidente que los nuevos huéspedes hispanos que de Europa siguen arribando a nuestras playas, costean su viaje con los auxilios que les brindan Negrín y Compañía, posiblemente hasta con fondos rusos, pues la satrapía roja del nuevo Iván el Terrible, como ahora se denomina al bárbaro y sanguinario Stalin, tiene los ojos especialmente puestos en nuestra patria, como el foco de las ideas bolcheviques que se quiere hacer penetrar a la nación vecina del Norte y para que inficione al resto del continente hispanoamericano. ${ }^{28}$

Para Omega, solo podían ser bien recibidos los españoles que siguieran al general Francisco Franco y que fueran católicos.

Aunque Omega era xenófobo y racista, no pensaba que en México fuera posible, tal vez ni siquiera deseable, alcanzar una homogeneidad racial. Sabía que en México sería difícil seguir los pasos de un fascismo como el de Alemania, ya que la composición racial del país era muy diferente: Omega reconocía el lugar central del mestizaje en la cultura nacional mexicana:

28 “Los Rojos españoles, escoria del desastre”, Omega, 27 de enero de 1940. 
Las probabilidades de que México se convierta en fascista son casi nulas, sólo el imaginarse que bandadas de mexicanos marchen con el brazo extendido exclamando "Heil" resulta ridículo... [...] Además, un factor indispensable para convertir a una nación en nazi debe ser una bien desarrollada conciencia de raza, que México no posee, ya que su población en gran parte consiste de una buena mezcla de sangre india y blanca. ${ }^{29}$

Omega no rechazaba la realidad mestiza mexicana, hasta podría pensarse que estaba orgullosa de ella, como dice el párrafo citado, era una "buena mezcla de sangre india y blanca”. Era más bien realista: la composición étnica de México era mestiza, no tenía caso pensar en compararla con la "pureza" de la raza blanca alemana. Por eso, ante la cuestión específica de la supuesta superioridad de la raza germana propia del nazismo, Omega tomaba su distancia: admiraba al pueblo alemán, alegando que era un "pueblo culto", pero opinaba que el alarde de superioridad racial era exagerado.

Esta "exageración” identificada por los columnistas del periódico podría deberse a los traductores de la obra de Hitler, a los que Omega acusaba de tergiversar el contenido, pero lo que interesa aquí es que para Omega la exaltación nazi de la raza germana era "exagerada", desmedida.

El antisemitismo y la xenofobia fueron características que Omega admiró en los dictadores europeos. Consideraba que los líderes políticos que combatían a los judíos, enfrentaban con ello amenazas de desestabilización y de comunismo; también que el mismo trato que se daba en Europa a judíos y "rojos" debía dárseles en México, por eso protestó en contra de la inmigración de españoles republicanos. Sin embargo, no compartió la idea de la limpieza de sangre, al menos no para el caso mexicano, y por lo tanto, tampoco la de la superioridad de una raza como la alemana. La raza mestiza mexicana tenía su razón de existir y sus propias posibilidades para transformar al país, a condición claro estaba, de no permitir la llegada de españoles republicanos y de recibir más bien, a elementos españoles profranquistas, por la misma idea de que España era considerada la madre patria.

29 Roberto Piña, "Del otro lado de la frontera", Omega, 28 de marzo de 1940. 


\section{El dictador católico}

Uno de los aspectos centrales de un gran líder, de un buen gobernante para Omega era el respeto a la religión católica. El catolicismo era uno de los ejes fundamentales del proyecto de nación de sus redactores, ya que lo consideraban una de las bases de la cultura mexicana y de toda Hispanoamérica. Gran parte de su admiración por Francisco Franco tenía que ver con que el general era un gran defensor de la fe católica. De la misma manera, en el otro extremo, parte importante de su rechazo hacia el presidente Lázaro Cárdenas era una respuesta a su propuesta educativa laica.

Para Omega, Francisco Franco es un gobernante ejemplar: "digan lo que quieran los enemigos y los decrépitos, es el conductor providencial de España, adornado con las galas del espíritu cristiano y con el corazón español, valeroso y esforzado". ${ }^{30}$

Este "espíritu cristiano" era de gran significado para el movimiento nacionalista español, para los falangistas, pero también para sectores fuertemente católicos como el movimiento carlista, que desde el siglo XIX defendía ideales monarquistas, conservadores y religiosos. Pero ese "espíritu cristiano" era también el responsable de que Franco fuera un dictador tan especial y digno de admiración para Omega, porque imponía un sello a su conducta.

En efecto, Omega reconocía que Franco había impuesto su poder por medio de las armas y que como gobernante, había suprimido libertades. Pero en una nota de octubre de 1941, uno de sus redactores afirmaba que Franco no puede ser considerado totalitario, porque "un gobernante católico siempre respetará a la Iglesia y a la familia, reconociendo el principio de autonomía de la persona humana". ${ }^{31}$ De esta manera, Omega afirmaba su admiración por la mano dura del gobernante y, si bien dejaba ver su menosprecio por las libertades individuales, aplaudía el respeto por dos instituciones: la familia y la Iglesia católica, para Omega, ejes de la sociedad y base de la civilización occidental. En su opinión Franco respetaba a las personas que abrazan estas instituciones y lo celebraban. Por el otro

30 Santos del Valle, "España y su caudillo (II parte)", Omega, 25 de mayo de 1939.

31 Luis G. Orozco D., "España y la guerra europea”, Omega, 18 de octubre de 1941. 
lado, Omega afirmaba que el ateísmo profesado por el comunismo era una amenaza a la religión católica del pueblo mexicano.

Para Omega, la defensa de la religión católica colocaba a Franco como un dictador, en alguna medida, superior a Hitler. Porque el nacionalsocialismo alemán era más bien irreligioso, carece de este "espíritu cristiano" del franquismo: "Es muy cierto que 'el hitlerismo profesa la idolatría de Alemania', y 'el comunismo adora [...] el proletariado' [...] Nuestros estimados 'antagonistas' también consideran que ambos beligerantes son idólatras y paganos". 32

De esta manera, tanto "rojos" como nazis renegaban de la fe católica y en ese punto eran comparables.

Omega era un entusiasta de las dotes y programas de Hitler, así como de la unidad del pueblo alemán, sin embargo le objetaba su rechazo a la Iglesia católica y a la fe cristiana en general. Pero Omega también sabía que Hitler no podía negar ni eliminar la religión de tajo, ya que una gran parte de la población alemana era católica. ${ }^{33}$ Por eso, Omega decía que Hitler reconocía a la familia como piedra angular de la sociedad y que permitía la existencia de las escuelas confesionales, aunque atacara a la religión y a los maestros libres: "Es cierto que en Alemania se ha implantado un sistema educativo nazi, contrario a la libertad de cátedra; mas se toleran los planteles particulares, donde enseñan los dogmas católicos o protestantes". ${ }^{34}$

Omega podía reconocer y apreciar un progreso a partir de la educación laica del siglo XIX, introducida por los reformadores liberales de la época, pero no la consideraba acabada, ni siquiera suficiente. Afirmaba que para que un país tuviera completa calidad moral, siempre le hará falta instrucción religiosa:

La escuela laica formó en nuestro México, cierta clase de personas, cultas e instruidas y muy estimables bajo diferentes conceptos, pero que en las cuestiones religiosas que son tan importantes en la vida del hombre y para la formación moral de los pueblos muestran gran ignorancia. Esto viene a demostrar que

32 Luis G. Orozco D., "¡Ya no hay paganos...!”, Omega, 17 de noviembre de 1941. 33 Albissy, Waffen SS, p. 18.

34 Luis G. Orozco D., "España y la guerra europea”, Omega, 18 de octubre de 1941. 
tal escuela, fue incompleta, ineficaz y nociva, menos dañoso es para la Patria combatir abiertamente la religión, como se hace en la escuela atea de ahora, que desconocerla hipócritamente, como lo haría el liberalismo; pues en el primer caso puede provocarse una reacción salvadora, como lo hemos presenciado ya en México. ${ }^{35}$

Omega reconocía que la formación laica podía cultivar a la gente, pero no le otorgaba una calidad moral. De esta manera, ignorar la religión tenía un efecto nefasto sobre el pueblo: lo tornaba moralmente ignorante. Omega prefería dar la lucha de frente contra quienes negaban la existencia de Dios y rechazaban la religión - los ateos, y hay aquí una referencia velada a Calles y a Cárdenas seguramente-, que vivir en un ambiente en que se respetaba toda creencia a condición de que no se enseñara en la escuela, lo que sería, en su opinión, el laicismo del siglo XIX.

Lo bueno, en cambio, de la instauración llamada educación socialista impulsada por el presidente Cárdenas era, en opinión de Omega, la reacción no solo de los religiosos, sino también de los padres de familia, que se opusieron a ella sacando a sus hijos de las escuelas por considerarlas "casas del diablo" y que de esa manera, impidieron que el gobierno volviera "ignorante" al pueblo de México.

En síntesis, una de las cualidades que Omega apreciaba más en un gobernante era su ferviente religiosidad, su carácter como devoto católico. Esta cualidad la admiró una y otra vez en Francisco Franco, a quien llegó a llamar "defensor de la fe" por el apoyo que dio a y recibió de la Iglesia católica. Omega creía que la religión católica era un elemento central, cohesionador de la sociedad mexicana, de gran valía por su carga identitaria a lo largo de toda la historia de México.

\section{El dictador autoritario}

Para Omega el gran político, el gran dirigente, debía ser antidemocrático. Porque la democracias occidentales en su opinión, habían demostrado sus limitaciones. Omega, al apoyar a los sistemas totalitarios europeos, asumía

35 Francisco González Franco, “El ateísmo del Señor Elorduy”, Omega, 4 de marzo de 1939. 
que la democracia como sistema era un fracaso, tanto político como económico, y pensaba que la manera de organización viable para el Estado, la que estaba probando su utilidad, era el fascismo. Así lo afirmó el 27 de julio de 1940: "el fascismo tiende a convertirse en la forma actual de organización de la política occidental". ${ }^{36}$

La antidemocracia era efectiva para sacar un país adelante, sostenía Omega, y la prueba la encontraba en el régimen encabezado por Hitler, quien estaba logrando poner fin a la crisis económica. Aplaudía el éxito económico de Hitler a partir de la supresión de la vida sindical y por ende, del derecho de los trabajadores a la participación política y a la libre defensa de sus derechos. Es por esto que comparaba la eficiencia del totalitarismo, del autoritarismo de Hitler frente a la ineficiencia de las democracias "clásicas" de Estados Unidos y la Gran Bretaña.

El periódico mexicano también sostenía que la caída de Francia en manos de los nazis en 1940 había sido, en parte, debido a su decrépito sistema democrático. Por eso aplaudía el resurgimiento de Francia como un Estado totalitario, a cuya cabeza estaba el mariscal Pétain, dictador que sacaría a su país de la ruina y lo haría renacer como una nación fuerte. Una de las manifestaciones en contra de las democracias anglosajonas se puede ver en este fragmento de un artículo aparecido en Omega:

Preferible es, o menos mala, la dictadura que un Hitler o un Mussolini han establecido en sus naciones, dándoles un vigor y una potencia que asombra, que no el "totalitarismo" encubierto con la máscara de una democracia corrompida e hipócrita, de origen judeo masónico, que Inglaterra y los Estados Unidos llevan puesta para engañar a las naciones de libertad a la vez que las esclavizan y explotan, hundiéndolas en la degeneración y en la miseria, como han hecho los Estados Unidos con México. ${ }^{37}$

En este caso, Omega acusaba al sistema norteamericano de esclavizar y explotar a México a pesar de decirse nación democrática. Por eso llamaba

36 Vinicio R. de la Vega, "El fascismo en Francia”, Omega, 20 de julio de 1940.

37 Francisco González Franco, "Nuestra revolución totalitaria”, Omega, 25 de abril de 1942. 
a su democracia "hipócrita y corrompida y de origen judeo masónico". El México posrevolucionario, en general, era antinorteamericano; también lo era esta facción de la derecha mexicana. Ante todo esto, los redactores de Omega preferirían tener un sistema totalitario franco, como el que en ese momento se vivía en Alemania o Italia, que una democracia abusiva como la norteamericana.

Sin embargo, aunque más partidaria del autoritarismo que de la democracia, Omega abogaba por una cierta tolerancia. La calidad de católico, por ejemplo, obligaba a definir ciertos límites para evitar excesos. Su ejemplo fue Francisco Franco, quien por ser católico, no podía ser "totalitario" realmente, pues pondría siempre por delante el respeto a la Iglesia y a la familia. ${ }^{38}$

Hitler podría ser ateo, sostenía Omega, aunque lo consideraba menos autoritario que otros regímenes como el de Stalin, completamente intolerante frente a la religión católica. La protección, e incluso la tolerancia frente a la práctica de la religión católica era una cualidad del dictador que Omega admiraba. Sin duda alguna, Francisco Franco era su gobernante predilecto, en este caso, por su respeto a la Iglesia y a la familia, pero Hitler le resultaba aceptable en este punto.

\section{El dictador y el comunismo}

Para Omega, como para muchos otros movimientos conservadores del siglo xx, el enemigo a vencer era la "barbarie roja", es decir, el comunismo. En la España de Franco ese enemigo era la república; en México, para el periódico, lo era el gobierno de Lázaro Cárdenas. Pero había un lugar en donde el comunismo había triunfado y contaba con un dictador poderosísimo al frente: la uRss de Stalin. Aunque Omega reconocía la capacidad de imponer orden de ese dictador, lo acusaba de sanguinario, así como de inconsecuente con sus propios principios.

En efecto, lo supieran o no los redactores de Omega con precisión, aquellos fueron los años de las grandes "purgas" de Stalin que costaron la

38 Luis G. Orozco D. “España y la guerra europea”, Omega, 18 de octubre de 1941. 
vida a miles de personas. ${ }^{39}$ Para Omega, Stalin sobrepasaba en 1941 el poder incluso de Iván el Terrible:

Gobierna como señor absoluto a la inmensa Rusia con sus 180.000 .000 de habitantes, sus ciento setenta y cinco diferentes razas y pueblos. Ninguno de los zares logró jamás reinar de modo tan firme y completo sobre esa abigarrada y heterogénea multitud de hombres. Ni Iván el Terrible, ni Pedro el Grande, ejercieron sobre sus súbditos un dominio tan cabal como el que ejerce hoy Stalin. ${ }^{40}$

La publicación acusó a Stalin de ser un tirano, pero también de traicionar sus ideales comunistas al asociarse con Alemania, un país con un régimen totalmente opuesto al soviético: de corte nacionalista, capitalista y abiertamente anticomunista. Esta acusación se refería en concreto a la firma del pacto germano-soviético, en agosto de 1939.

Omega reconocía los liderazgos de Lenin y de Trotsky, pues a pesar de que eran comunistas, también eran "intelectuales". Pareciera que el carácter de intelectual era algo valioso para Omega, aunque no desarrolló más esta idea. Pero frente a ellos, aunque los intelectuales tuvieran ideas comunistas, Stalin fue retratado como un dictador totalitario, salvaje y ajeno a ideología política alguna. Stalin, sostenía Omega, "es el hombre más adulado, más temido y más odiado a la vez de cuantos existen". ${ }^{41}$ Pero era político hábil y el periódico lo reconoció como el hombre más poderoso de la tierra: "Con una paciencia y un tesón sólo comparables a los que emplea un avaro en acumular oro, Stalin ha ido reuniendo en sus manos todos los hilos del poder político. Stalin es, sin género de duda, el mortal más poderoso de nuestros días". ${ }^{2}$

Ante esta afirmación, Stalin quedó representado como un dictador enfermo de poder que había sometido a la población que le había heredado Lenin y que la doblegó por medio del miedo.

39 Nolte, La guerra civil europea, p. 245.

40 Eugene Lyons, "Stalin, zar de todas las Rusias", Omega, 24 de mayo de 1941.

41 Ídem.

42 Ídem. 
Para el periódico, el gran poder de Stalin era reprobable porque carecía de ideales. No le reconocía siquiera el compartir la ideología de Lenin y Trotsky. De esta forma, para Omega no existía un dictador comunista digno de alabanza. Solo respetaba dictadores de derecha.

\section{El dictador y la intervención en la economía}

Durante las décadas de los veinte y los treinta, el ascenso de los Estados totalitarios significó el ensayo de nuevas formas de organización tanto política como económica. Así como esos Estados rechazaban la democracia como camino para alcanzar la justicia social, cuestionaron también la eficacia de la libre competencia para el crecimiento económico.

Tanto la Unión Soviética como la Alemania nazi y la Italia fascista llevaron a cabo políticas económicas intervencionistas. La primera expropió la propiedad privada a favor del Estado e implantó una economía planeada que buscó una rápida industrialización. Las segundas -Alemania e Italiapromovieron otro sistema de economía dirigida: respetaron la propiedad capitalista sobre tierras y fábricas, pero el Estado controló su producción.

Pero Omega no coincidió en este punto con los dictadores europeos; por el contrario, rechazó enérgicamente la intervención del Estado en la economía, cualesquiera que fuera la orientación ideológica que justificara tal intervención, fuera de izquierda o de derecha, porque

Cuando la libre competencia, que es la vida del comercio y de las industrias, se suprime, el acaparamiento y los monopolios, hacen su aparición, y como resultado lógico los pequeños industriales y comerciantes así como los consumidores, resultan lesionados en sus más caros intereses... ${ }^{43}$

¿Qué intereses defendía Omega desde esta postura? Los de los propietarios grandes y medianos, posiblemente los de propietarios rurales, a quienes golpeaba la reforma agraria cardenista, o bien los tres grupos de comerciantes o empresarios a quienes afectaban los planes de producción que el gobierno

43 “La 'economía dirigida' totalitaria roja nos hundirá en un pavoroso desastre", Omega, 12 de enero de 1939. 
mexicano buscaba imponer. Según Omega, la defensa de la libre empresa era vital para el desarrollo económico de México y por ello reprobaba el Plan Sexenal, adoptado por el gobierno posrevolucionario de Lázaro Cárdenas: "Aquí se abomina de los regímenes totalitarios de Mussolini y Hitler, y con una burda imitación, se trata de implantar el mismo procedimiento, que en vez de dirigir la economía, la desorienta y la perturba, en beneficio de unos cuantos para sacrificar la inmensa mayoría". ${ }^{44}$

Omega criticaba así al gobierno mexicano, pero también reprobaba la manera en que Hitler y Mussolini estaban dirigiendo la economía de sus respectivos países. También ellos, en su opinión, "desorientan", "perturban" y "sacrifican mayorías". Podía admirar a los dictadores europeos, pero se opuso a sus políticas económicas en contra de la libre empresa y de las libertades de los propietarios.

Las posturas en materia económica del antidemócrata Omega ponían en evidencia la falta de solidez del discurso de sus redactores: el periódico no quería que el Estado limitara libertades económicas, pero sí políticas; exigía respeto al derecho a la propiedad, pero no a la libertad de expresión y asociación. Era un periódico asociado a determinados intereses económicos y poco comprometido con un discurso ideológicamente coherente.

\section{Conclusión}

A pesar de la simpatía que Omega tenía por los regímenes totalitarios de derecha, por el fascismo y por la manera en que algunas de las potencias europeas estaban llevando a cabo sus políticas nacionalistas, xenofóbicas y autoritarias, sus redactores no estaban de acuerdo con todo lo que hacían dictadores como Hitler o Mussolini. Ninguno de los dictadores europeos por sí mismo parecía ser el gobernante ideal para Omega, aunque Franco se acercaba bastante al modelo deseado por sus redactores.

De todas formas, los columnistas de Omega podían tomar de cada dictador lo que mejor les pareciera: de Franco, el "salvador de la fe", aplaudían su ferviente catolicismo, además de sus habilidades militares; de Hitler alababan la manera en que había levantado a la nación alemana tanto moral

44 Ídem. 
como económicamente, así como su exaltación nacionalista y su decidido anticomunismo, aunque criticaban su falta de compromiso con la religión cristiana y su política de intervención en la economía. Y con el aplauso o reprobación a posturas y acciones de los jefes de Estados autoritarios de finales de los treinta y principios de los cuarenta del siglo xx, Omega hacía el retrato del gobernante que quería para México.

Vale la pena apuntar que en 1940, Omega se comprometió no solo con campañas anticardenistas, sino con un candidato a la presidencia de la república mexicana: apoyó al general Juan Andreu Almazán, quien contendió con Manuel Ávila Camacho, el candidato apoyado por el partido de Lázaro Cárdenas. Almazán era un militar conservador, respaldado por clases medias y grupos clericales; era una figura que, a decir de Omega, poseía todas las cualidades necesarias para dirigir al país y detener los programas" socialistas" que tanto daño hacían, en su opinión. De esta manera, el retrato del "dictador ideal" del trisemanario era asociado, por el propio Omega al candidato apoyado. Antidemocracia política, nacionalismo y xenofobia, militarismo y libertad económica, resumen el programa de Omega para el México de 1939-1942. Posiblemente Almazán no representaba todo esto en 1940, pero fue la figura que a la publicación le pareció entonces la más cercana a su proyecto para México.

Adentrarse en el tema que hemos desarrollado en este artículo permite conocer otros proyectos de nación que hacia mediados del siglo xx, existieron también para México. El Omega, era un proyecto que tenía uno de los grupos políticos conservadores más radicales que había en ese entonces, un grupo conformado por sectores de clases medias y altas, que buscaba integrarse a la política del país de acuerdo con sus intereses. Era un proyecto que hoy podremos rechazar por sus ideas negativas como el racismo, el nacionalismo y el autoritarismo, pero que necesitamos conocer si queremos saber qué tanto peso llegó a tener en su momento y en el fin del radicalismo revolucionario que representó el gobierno de Lázaro Cárdenas en aquellos años.

Durante el periodo de gobierno cardenista, la derecha radical mexicana tenía simpatizantes de varios sectores sociales y el periódico Omega, que expresaba muchas de sus ideas, pasó de ser una publicación semanal a un bisemanario, y después a un trisemanario. O sea que Omega tuvo lectores, 
es decir, seguidores. Sus críticas al gobierno de Cárdenas, su apoyo a Juan Andreu Almazán en 1940, en contra del candidato para presidente de México que Cárdenas apoyaba, y sus aplausos a los dictadores europeos deben haber tenido un peso en la política de esos años. Debemos conocer todo esto para entender mejor cómo fue disminuyendo el radicalismo de la revolución y cómo se fue conformando el México de la segunda mitad del siglo xx. Por eso, entender el proyecto de Omega es de alguna manera, entender cómo el radicalismo revolucionario del general Cárdenas se vio obstaculizado por fuerzas que defendían el control de los movimientos sociales, el catolicismo como elemento de unidad e identidad de los mexicanos, el respeto a la propiedad privada y la libertad de empresa.

\section{Fuentes}

\section{Hemerografía}

Omega, ciudad de México, 1939-1942

\section{Bibliografía}

Ailsby, Christopher, Waffen SS. La guardia negra de Hitler en la guerra, Madrid, LIBSA, 2002.

Bulnes, Francisco, El verdadero Díaz y la revolución. Rectificaciones y aclaraciones a las memorias del general Porfirio Díaz, estudio introd. y notas Alicia Salmerón, México, Instituto Mora, 2008.

Campbell, Hugh, La derecha radical en México, 1929-1949, México, SEP, 1976. Canetti, Elías, Masa y poder, España, Muchnick, 1985.

Chacón, Susana, "La negociación del acuerdo militar entre México y los Estados Unidos, 1940-1942”, en Foro Internacional, vol. 40, núm. 2 (160), abril- junio 2000, pp. 307-344.

Gleizer Salzman, Daniela, El exilio incómodo. México y los refugiados judios, 1933-1945, México, El Colegio de México/uam-C, 2011.

Gueniffey, Patrice, "La voluntad en la historia”, en Istor, 2004, año V, núm. 17, pp. 3-19. 
Gojman de Backal, Alicia, Camisas, escudos y desfiles militares. Los dorados y el antisemitismo en México (1934-1940), México, UNAM/FCE, 2000.

Hitler, Adolf, Mi lucha, México, Partido Nacional Socialista de América Latina, 2000.

León y González, Samuel (coord.), El Cardenismo 1932-1940, México, FCE, 2010.

Meyer Cosío, Lorenzo, "De la nacionalización a la segunda guerra mundial", en México para los mexicanos. La revolución y sus adversarios, México, El Colegio de México, 2010, p. 397-491.

Meyer Cosío, Lorenzo, "El conflicto petrolero entre México y los Estados Unidos (1938-1942)", en Foro Internacional, vol. 7, núm. 1/2 (25-26) juldic. 1966, pp. 99-159.

Nolte, Ernst, La guerra civil europea, 1917-1945. Nacionalsocialismo y bolchevismo, México, FCE, 1994.

Ortiz Garza, José Luis, Ideas en Tormenta. La opinión pública en México en la segunda guerra mundial, México, Ruz, 2007.

Pérez Montfort, Ricardo, Hispanismo y Falange. Los sueños imperiales de la derecha Española, México, FCE, 1992.

Pérez Montfort, Ricardo, Por la patria y por la raza. La derecha secular en el sexenio de Lázaro Cárdenas, México, UNAM-FFyL, 1993.

Pérez Rosales, Laura, "Notas sobre anticardenismo y antisemitismo en México. 1934-1940”, en Historia y Grafía, 1995, núm. 2, año I, pp. 180202.

Reggiani, Andrés, "Vichy y los historiadores", en Los años sombríos. Francia en la era del fascismo 1934-1944, Buenos Aires, Miño y Dávila, 2010, pp. $39-84$

Rodríguez Aviñoá, Pastora, "La prensa nacional frente a la intervención de México en la segunda guerra mundial", Historia Mexicana vol. 29, núm. 2, octubre-diciembre 1979, pp. 252-300.

Savarino, Franco, "Fascismo en América Latina, la perspectiva italiana, (1922-1943)", Diálogos, 2010, vol. 14, núm. 1, pp.39-81.

Servín, Elisa, "Entre la Revolución y la reacción: los dilemas políticos de la derecha”, en Erika Pani, Conservadurismo y derechas en la historia de México, México, Fondo de Cultura Económica, 2009, t. II, pp. 467-511. 